\title{
Photoluminescent Pigment Printed Textiles for Home Fashion: A User Preference Study
}

\author{
Richa Sharma ${ }^{1 *}$ and Nilanjana Bairagi ${ }^{2}$ \\ ${ }^{1}$ Textile Department, National Institute of Fashion Technology, India \\ ${ }^{2}$ Knitwear Department, National Institute of Fashion Technology, India
}

Submission: October 03, 2019; Published: October 29, 2019

*Corresponding author: Richa Sharma, Textile Department, National Institute of Fashion Technology Bengaluru, 560102, India

\begin{abstract}
User preference study is an exploratory approach to assess the potential of photoluminescent pigment printed textiles as end products. The user goals need to be identified for the possible end use in the given context. For products like home fashion, personalisation and aesthetics are important factors for the success of the product. Photoluminescent pigments are rare earth metals that absorb light and emit it slowly as a pale blue/bluish green light. The duration of glow may sustain over 6-8 hours after initial excitation from external light source. Therefore, these pigments may be used for designing textiles for home to enable edge definition and navigation in the dark. The experimental studies establish that with the increase in concentration of photoluminescent pigment in printed textiles the luminosity increase [1]. But there are limited studies to correlate this data with the user and their preferences for end-use as photoluminescent pigment printed textile in dim lighting condition.

Keywords: Photoluminescent pigments; Luminosity; Lighting condition; Printed textiles; Visual perception; Home fashion
\end{abstract}

\section{Research Methodology}

It has been reported in the literature that the products designed should be familiar and tangible for greater acceptability by the user [2].The study needs to focus not only on the user needs but also on the context that challenges the need in the journey of product development [3]. Therefore, this user perception study was conducted in a dark room; closest context of a real environment was created followed by a questionnaire method to record user perception and assign attributes to the afterglow of the photoluminescent pigment printed textiles that the user experienced. For identification of the complete spectrum of user needs informant design or participatory approach to design was also encouraged to explore diversity in the product categories [4].

\section{Participants}

The study was conducted with 60nos. participants in the age group of 19-60years with a mix of both normal and corrected vision. The study was done individually and none of the participants were allowed proximity to interact or influence the findings. Out of 60 only 22 wore glasses for corrected vision. The researcher methodically noted the observations made by individual user and details of the findings from the questionnaire are collated and presented hereafter.

\section{Stimuli}

The dark room set was created with scotopic lighting closing all the natural sources of light with black paper under dark curtains. One long table was arranged and all the 24 printed samples B1-B4 and G1-G4 in C3 (5\%), C4 (10\%) and C5 (20\%) concentrations as depicted in Figure 1 were placed at random in rows. The participants were brought in blindfolded after acclimatization at low light and made to enter the dark room.

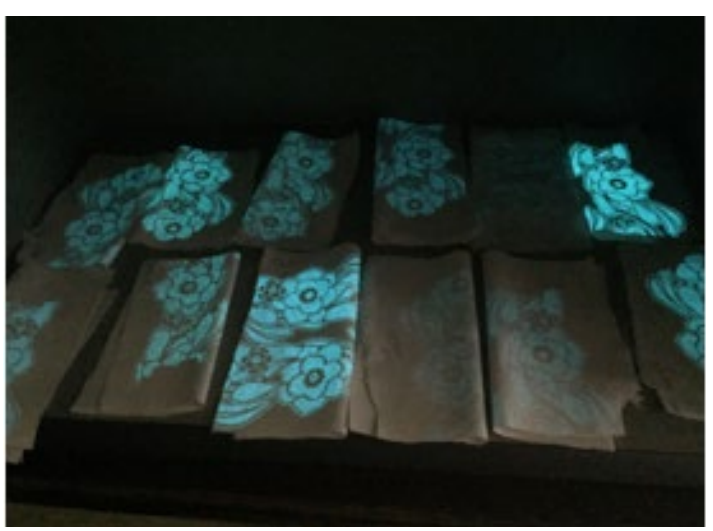

Figure 1: (a) Blue photoluminescent pigment printed textile samples at variable concentration (top).

\section{Research Findings of the User Preference Study}

The main aim of this study was to understand the user preferences and user behaviour with respect to photoluminescent pigment printed samples.

First Reaction: The first reaction of the participants was of excitement and joy. The novelty of the phenomena, the 
light coming from textiles as the room is put to darkness was inescapable. The impact of novelty is there and thus stirred emotion in all participants.

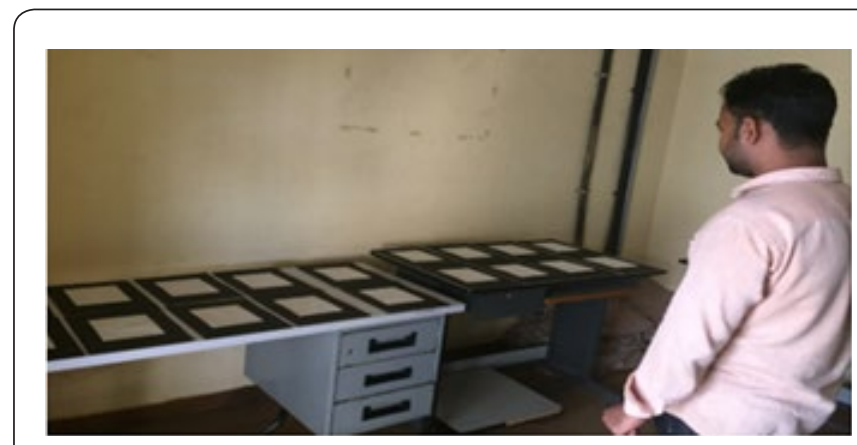

Figure 1: (b) Dark room set up for User Preference Study (bottom).

Description of Light: The description of light is without any glare. The light from the glow was steady and not flickering. The perception of light was coming from the printed textile samples instead of being reflected. In the user preference study $95 \%$ of participants reported no glare and discomfort with the light from the afterglow of photoluminescent pigment. The light appeared brighter as it was approached and thus a perception of depth was present. All the participants recorded the details of the pattern and described it as floral which suggests that the luminosity emitted by the printed samples is significantly perceptible in the dark.

\section{Categorization of Samples}

Table 1: Categorization of Swatches.

\begin{tabular}{|c|c|c|c|}
\hline Pigment & C3 & C4 & C5 \\
\hline B4 & 19 & 11 & 15 \\
\hline B3 & 12 & 3 & 14 \\
\hline B2 & 1 & 8 & 9 \\
\hline B1 & 23 & 18 & 10 \\
\hline G4 & 13 & 16 & 5 \\
\hline G3 & 6 & 2 & 17 \\
\hline G2 & 4 & 21 & 22 \\
\hline G1 & 24 & 7 & 20 \\
\hline
\end{tabular}

The second task was to segregate the 24 samples into three categories i.e. Very Bright, Moderate and Least Bright. The Figure 2 shows the distribution of the choices made by the participants on random numbers assigned to the samples. The findings are in line with the experimental results where the visual perception of the samples increases from least bright to very bright as the concentration of the pigment increases irrespective of the particle size(Sharma and Bairagi, 2019). As observed in Table 1 the brightest samples are seen mostly as C5 (20\%), moderate at C4 (10\%) and least bright at C3(5\%) concentration respectively.

\section{Natural Light Sources Compared to Photoluminescent Print}

Engagement of the photoluminescent printed textile with the user can be further understood with the quality of light and possible end uses which they can visualize and adopt in daily living. Intensity of acceptable perceived luminescence for night-light was thus recorded. As per the findings the participants related to starlight with 'Least Bright' category, oil lamps for 'Moderate' and full-moon light with 'Very Bright'. This distribution is illustrated graphically in Figure 2.

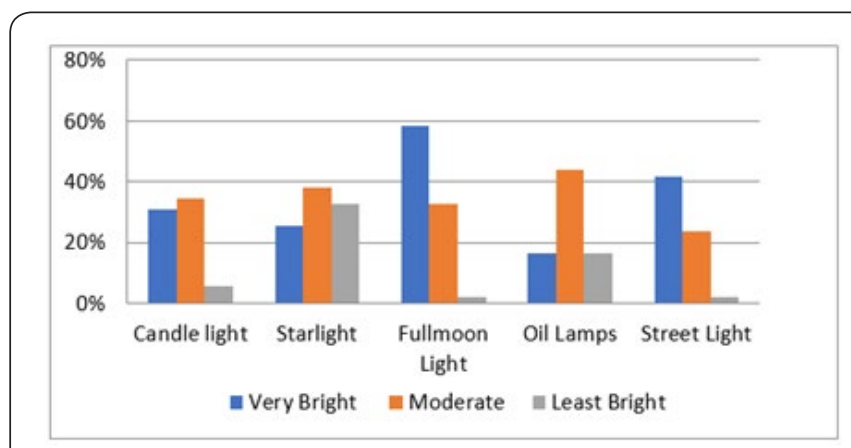

Figure 2: User preference of leaving the lights on during night even when it is not in use.

\section{User Selection of Leaving a Room Lit During Night Even When not in Use}

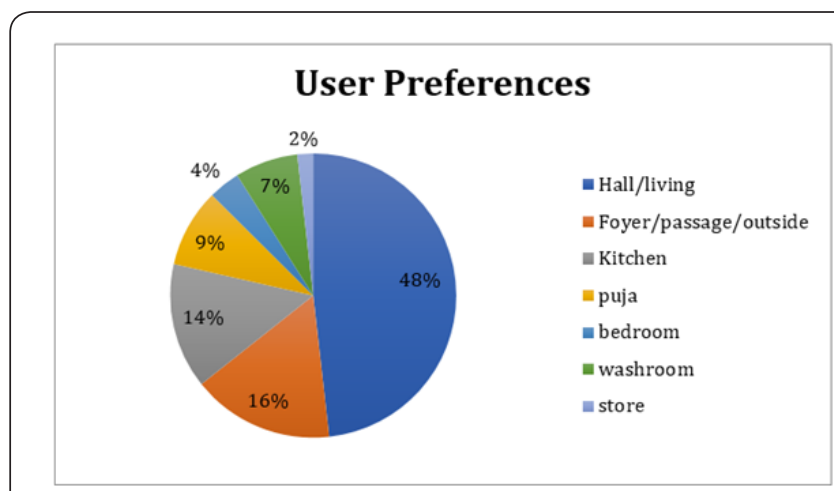

Figure 3: Natural light sources Compared to Photoluminescent Print.

As per the survey we find that most participants prefer to leave their hall/ living rooms with some level of illumination. As graphically represented in Figure 3 we find that we have $49 \%$ of the participants for hall/ living which is more than two times the next preceding option of foyer or the kitchen.

\section{Sleeping Preference}

With respect to the user preference for keeping the lights on during sleep at night, more than $50 \%$ of the participants responded that they don't sleep in complete darkness even though only $10 \%$ leave the lights on. $40 \%$ of the participants were open to the idea of using night lights in their bedrooms. Many reported light trespass from corridors and streetlights into their rooms at night.

\section{Preference of Luminosity for Nightlamp}

The preference of intensity for night light based on the category identified by the participant in the beginning is 
illustrated in Figure 4 which is Very Bright, Moderate and Least Bright. The distribution is significant for very bright and moderate, but every category is significantly represented which means that there is a need for personalization in the product.

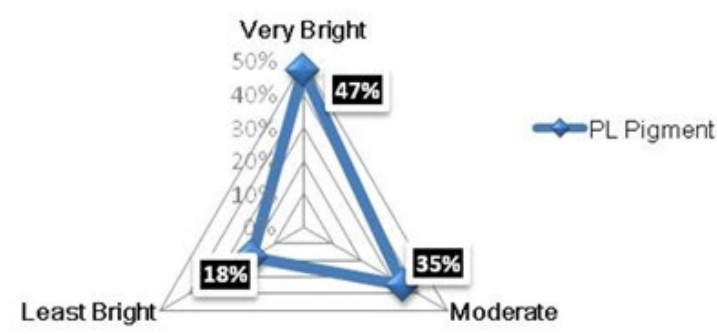

Figure 4: Preference of Intensity for Night Lamp.

\section{Attribute Emotive Quality to the Photoluminescence from the Fabric Samples}

To take into account tangibility of the product it was important to ascribe emotive attributes with the afterglow, which will help us in design and function. The users correlated the photoluminescent light with extreme emotions like excitement and joy for the bright samples while sad and lonely was attributed to least bright samples. Moderately bright samples appeared calm and few responses were given to fear leaning towards least bright samples.

\section{User Aspirations}

This survey emphasizes the user needs and aspirations where $80 \%$ users were willing to experiment with new photoluminescent printed products. This poses a huge opportunity for design and emerging new markets.

\section{Preference of Product Category}

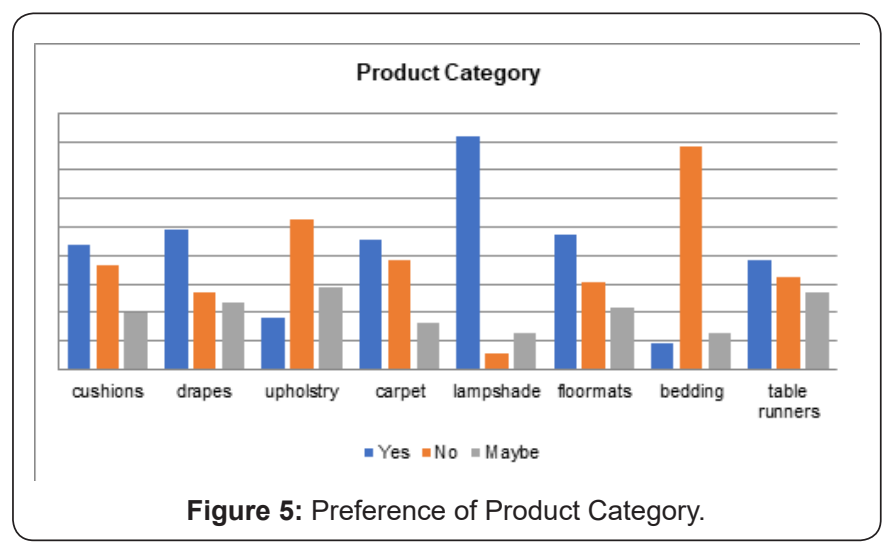

Most of the users associated with lampshades as a product category. Cushions, drapes, carpets, floor-mats, table runners etc. had a mixed response. Many novel suggestions like puja room diyas, wallets and linings of bags, fridge handle covers, and bathroom handles etc. were also mentioned. Figure 5 clearly shows that the design possibilities for this print in homes is tremendous and needs to be explored.

\section{Mapping New Product Categories and Opportunities}

Based on the suggestions and inputs from the participants the following mind map [Figure 6] was made to capture the emerging areas where the design may be extended for future scope and work. New categories such as key chains and fridge door handles, wallet and spectacle covers, linings for bags, puja accessories like garlands and diya's, Christmas decorations and many such opportunities opens research and experimentation areas for future work. As the intensity of photoluminescence emitted is below 1lux, it would have no impact on the circadian rhythm of human beings as per the literature. It is thus seen as probable applications in the area of healthcare, elderly care, infants and baby care products and people suffering from insomnia and sleeping disorders. It could also be used in places like nightclubs, lounge bars and dance halls where low lighting is the norm. And intended use for activities where too much light could be an impediment such as meditation, listening to music and lovemaking could also be considered. The photoluminescent products may be integrated into the fitness gear for running and cycling, especially in paths where lighting maybe obscure. Camping gear like tents and sleeping bags could be a possibility. Also, garden and patio upholstery maybe designed for enjoying the natural nightlight.

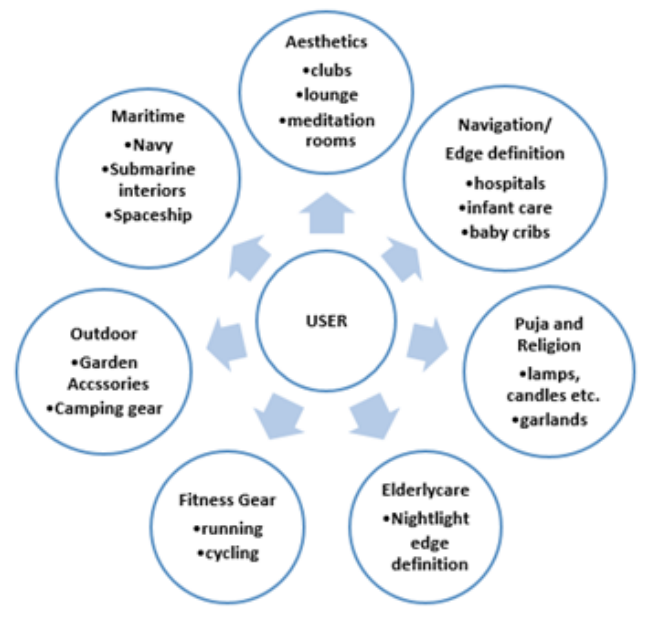

Figure 6: Mind map of user needs and preferences.

\section{Conclusion}

The user preference study emphasised that there is a huge potential for design development for new product categories for photoluminescent pigment printed textiles not only in the area of home fashion but also newer market positioning such as camping and fitness gear, maritime use and navigation aids for elderly and baby care to mention a few.

\section{References}

1. Sharma R, Bairagi N (2019) Photoluminescent Printed Fabrics: An Innovative Solution to Natural Nightlight. Functional Textiles and Clothing pp. 107-117. 
2. Monk Andrew (2000) User-Centred Design : The Home Use Challenge. Home informatics and telematics: information technology and society pp. 181-190.

3. Kujala S, Kauppinen M, Rekola S (2001) Bridging the Gap between User Needs and User Requirements. Advances in Human-Computer Interaction I pp. 45-50.
4. Scaife M, Rogers Y, Aldrich F, Davies M (1997) Designing for or designing with? Informant design for interactive learning environments. Human Factors in Computing Systems pp. 343-350.

\begin{tabular}{|l|}
\hline \multicolumn{1}{|c|}{ Your next submission with Juniper Publishers } \\
will reach you the below assets \\
- Quality Editorial service \\
- Swift Peer Review \\
- Reprints availability \\
- E-prints Service \\
- Manuscript Podcast for convenient understanding \\
- Global attainment for your research \\
- Manuscript accessibility in different formats \\
( Pdf, E-pub, Full Text, Audio) \\
- Unceasing customer service \\
Track the below URL for one-step submission \\
https://juniperpublishers.com/online-submission.php
\end{tabular}

